\title{
UMA ANÁLISE INTERDISCIPLINAR DA INTERRUPÇÃO DA GRAVIDEZ DE FETO ANENCEFÁLICO
}

FRANCISCO VIEIRA FILHO 


\section{UMA ANÁLISE INTERDISCIPLINAR DA INTERRUPÇÃO DA GRAVIDEZ DE FETO ANENCEFÁLICO ${ }^{1}$}

Francisco Vieira Filho ${ }^{2}$

"O maior insulto à santidade da vida é a indiferença ou a preguiça diante de sua complexidade." (Ronald Dworkin)

\section{RESUMO}

0 objetivo deste artigo científico é analisar o fato interrupção da gravidez de feto anencefálico à luz dos direitos à vida do feto e da saúde e liberdade da gestante, bem como dos princípios constitucionais da dignidade da pessoa humana e da legalidade, sem se afastar de analisar algumas questões ético-jurídicas surgidas do debate do tema com enfoque, igualmente, na conseqüência penal da conduta.

\section{Palavras-Chave:}

Anencefalia, abortamento, dignidade da pessoa humana, atipicidade.

\section{RESUMEN}

El objetivo de este trabajo es analizar el efecto de la interrupción del embarazo de feto anencefálico a la luz de los derechos a la vida y la salud del feto y la libertad del gestante, así como los principios constitucionales de la dignidad humana y la legalidad, no de mirar de lado algunos problemas éticos y jurídicos que se derivan de la discusión de este tema con especial atención también sobre el resultado de una conducta criminal.

\section{Palabras llave:}

Anencefalia, abortamento, dignidad de la persona humana, atipicidad.

\footnotetext{
${ }^{1}$ Artigo produzido no Curso de pós-graduação lato sensu em Direito Constitucional oferecido pela Universidade do Tocantins - UNITINS.

${ }^{2}$ Pós-graduando em Direito Constitucional pela Universidade do Tocantins - UNITINS e Juiz de direito titular da $1^{\mathrm{a}}$ Vara Criminal da Comarca de Araguaína/ TO.
} 


\section{INTRODUÇÃO}

0 homem é um ser gregário por natureza. Das relações sociais surgem inexoravelmente conflitos de interesses, que nas sociedades civilizadas passaram a ser regulados pelo Direito. Com efeito, ensina Bobbio (2004, p. 72):

Encontrando-se num mundo hostil, tanto em face da natureza quanto em relação a seus semelhantes, segundo a hipótese hobbesiana do homo homini lupus, o homem buscou reagir a essa dupla hostilidade inventando técnicas de sobrevivência com relação à primeira, e de defesa com relação à segunda. Estas últimas são representadas pelos sistemas de regras que reduzem os impulsos agressivos mediante penas, ou estimulam os impulsos de colaboração e de solidariedade através de prêmios.

A regra, ainda, é a maior expressão do Direito em nosso país e isso se deve principalmente à influência da doutrina liberal da tripartição de poderes na formação daqueles que são investidos da atribuição de criá-las e da competência de interpretá-las. 0 dinamismo das relações sociais antes mencionado, especialmente aumentado pela globalização, comunicação em massa e progresso tecnológico, impede o acompanhamento por parte das regras da disciplina de todas as situações surgidas e por surgir que demandam solução.

Como é cediço, a aplicação das regras em casos concretos necessita de uma atividade intelectiva de atribuição de significado aos termos nelas contidos. Essa atividade, atualmente exercida precipuamente pelo Poder Judiciário, está sendo desenvolvida não somente à luz de fatores históricos, sociológicos, econômicos, etc., mas, sobretudo, sob a influência de comandos constitucionais explicitados em princípios e regras que formam o arcabouço jurídico brasileiro.

É a chamada constitucionalização do direito, termo de uso relativamente recente na terminologia jurídica e que comporta pelo menos dois sentidos. 0 primeiro é o fato de temas de direito infraconsti- 
tucional estarem plasmados no seio da Lei Fundamental de um povo, e o segundo é o fato de que todo tema de direito infraconstitucional deve ser analisado e abordado com as "lentes da Constituição" porque sofre a repercussão de seu conteúdo. É dizer, deve conformar-se com a decisão política tomada e materializada no seio da Lei Maior.

Segundo Fernandes ( 2007, pp. 111 - 112):

Estima-se que já tenham sido proferidas pelo Judiciário brasileiro, aproximadamente, 3.000 (três mil) autorizações permitindo a interrupção da gravidez em casos de incompatibilidade com a vida extra-uterina. Não se trata, portanto, de casos isolados, desmerecedores de apreciação e pesquisa; ao contrário, a despeito das aparências, já existe jurisprudência específica sobre o assunto no Brasil, há pelo menos quinze anos.

É especialmente sob este último prisma de análise constitucional da interrupção da gravidez de feto anencefálico e sua repercussão no direito penal-constitucional que este artigo abordará o tema, sendo esta, portanto, a opção metodológica do presente estudo, pois "essa tensão entre seguir o Direito e desafiá-lo de modo criativo e transformador é uma tensão que não podemos eliminar de nossas vidas". (BANKOWSKI, 2007, p. XI).

\section{O QUE É ANENCEFALIA?}

Para que o tema possa ser compreendido é necessária antes uma incursão em questões terminológicas com o auxílio de outra ciência (interdisciplinaridade), no caso a Medicina, o que se faz doravante.

Anencefalia quer dizer má-formação fetal congênita por defeito do fechamento do tubo neural durante a gestação, de modo que o feto não apresenta os hemisférios cerebrais e o córtex, havendo apenas resíduo do tronco encefálico. É conhecida vulgarmente como "ausência de cérebro".

Enfim, é uma "anomalia do sistema nervoso central que se ca- 
racteriza, genericamente, pela ausência da abóboda craniana, massa encefálica reduzida a vestígios da substância cerebral". (REZENDE, 1969, p. 865). Trata-se, dentre os casos de má-formação fetal incompatível com a vida, do mais comum, acontecendo na proporção de um caso a cada registro de mil e seiscentos nascidos vivos. Ressalte-se que os números de registros de nascimentos com vida no Brasil têm oscilado entre 2,7 e 3 milhões /ano. Este país, segundo a Organização Mundial de Saúde, ocupa a quarta posição no mundo em ocorrência de anencefalia (cf. FERNANDES, 2007, p. 113).

0 exame que a diagnostica é denominado ecografia (espécie de ultra-sonografia) e detecta a anomalia com índice de erro praticamente nulo. Não existe, enfim, a possibilidade de tratamento ou reversão do problema, pelo menos na quadra atual da medicina, tanto que as soluções éticas preconizadas para o caso são duas:

Quando o diagnóstico é realizado nos dois primeiros trimestres da gravidez, a conduta é a sua interrupção induzida com misoprostol, após ouvir os familiares e obter o alvará judicial (até que seja regulamentada essa indicação de abortamento). Quando a identificação da anencefalia é tardia, eventualmente pode ser discutido com os pais o prosseguimento da gravidez até o termo, visando ao aproveitamento dos órgãos do concepto para transplantes. (ALVES, 2006, p. 673).

\section{O QUE É ABORTAMENTO PARA A MEDICINA?}

Abortamento deriva do latim abortu, abortare. Ab quer dizer privação e ortus nascimento. Vale dizer, impedir o nascimento.

Já a Enciclopédia e Dicionário Koogan/Houaiss diz que abortamento significa "expulsão provocada ou consentida do produto da concepção, com o propósito de obstar que ele venha a ter qualquer possibilidade de vida extra-uterina".

Segundo a Organização Mundial de Saúde (OMS), o abortamento consiste atualmente na interrupção da gestação com feto pesando até 
quinhentos gramas ou com idade gestacional inferior a 22 semanas, o que equivale a aproximadamente o quinto mês de gestação. Acima dessa idade ou peso, para a Medicina, trata-se de parto prematuro ou prematuridade, conforme ensinamentos dos Professores Jorge de Rezende \& Carlos Antônio Barbosa Montenegro.

As palavras abortamento e aborto são erroneamente utilizadas como sinônimas. Abortamento é o processo de expulsão do feto, enquanto aborto se refere ao feto eliminado, ou seja, ao produto do abortamento.

Do ponto de vista médico, não é equivocado o termo abortamento com o significado de antecipação da expulsão do feto anencéfalo do ventre materno por meio artificial (ou mesmo natural) antes do termo.

\section{E PARA O DIREITO, O QUE É ABORTAMENTO CRIMINO- SO?}

Para o direito, abortamento criminoso consiste na "cessação de gravidez, antes do termo normal, causando a morte do feto, sem que a conduta esteja acobertada pelas excludentes de ilicitude previstas no artigo 128 do Código Penal". (NUCCI, 2002, p. 390). A doutrina jurídica reconhece as seguintes espécies de abortamento, a saber:

a) Abortamento natural: é a interrupção da gravidez oriunda de causas patológicas e que ocorre de maneira espontânea. Neste caso não há crime.

b) Abortamento acidental: é a cessação da gravidez por conta de causas exteriores e traumáticas, como quedas e choques. Neste caso não há crime também.

c) Abortamento permitido ou legal: é a cessação da gestação, com a morte do feto, admitida por 
lei. Esta forma subdivide-se em:

1) Abortamento terapêutico ou necessário: é a interrupção da gravidez realizada por recomendação médica, a fim de salvar a vida da gestante. Trata-se de espécie de estado de necessidade. Exclui a ilicitude do fato.

2) Abortamento sentimental ou humanitário: é a autorização legal para interromper a gravidez quando a mulher foi vítima de estupro. Exclui a ilicitude do fato também.

d) Abortamento criminoso: é a interrupção forçada e voluntária da gravidez, provocando a morte do feto. Nesta modalidade há a inclusão do abortamento econômico-social, que é a cessação da gestação, causando a morte do feto, por razões econômicas ou sociais, quando a mãe não tem condições de cuidar do seu filho, seja porque não recebe assistência do Estado, seja porque possui família numerosa, ou até por política estatal.

e) Abortamento eugênico ou eugenésico: é a interrupção da gravidez, causando a morte do feto, para evitar que a criança nasça com graves defeitos genéticos. (Id. pp. 390-391).

0 abortamento de feto anencefálico, para o Direito Penal dogmático apegado à letra fria da lei e despido de interpretação conforme a Constituição, é crime. Aliás, outro não foi o entendimento do Superior Tribunal de Justiça ao julgar o recurso de Habeas Corpus no 32.159, cuja relatora foi a Ministra Laurita Vaz, senão vejamos: 
HABEAS CORPUS. PENAL. PEDIDO DE AUTORIZAÇÃO PARA A PRÁTICA DE ABORTO. NASCIDO ACOMETIDO DE ANENCEFALIA. INDEFERIMENTO. APELAÇÃO. DECISÃO LIMINAR DA RELATORA RATIFICADA PELO COLEGIADO DEFERINDO O PEDIDO. INEXISTÊNCIA DE PREVISÃO LEGAL. IDONEIDADE DO WRIT PARA A DEFESA DO NASCITURO.

(...)

4. 0 Legislador eximiu-se de incluir no rol das hipóteses autorizativas do aborto, previstas no artigo 128 do Código Penal, o caso descrito nos presentes autos (nascituro acometido de anencefalia). 0 máximo que podem fazer os defensores da conduta proposta é lamentar a omissão, mas nunca exigir do Magistrado, intérprete da Lei, que se lhe acrescente mais uma hipótese que fora excluída de forma propositada pelo Legislador. (GOMES, 2007, pp. 77 - 78).

\section{DIREITO À VIDA DO NASCITURO PORTADOR DE ANEN- CEFALIA VERSUS DIREITO À SAÚDE DA GESTANTE}

Talvez incentivado pelo tópico o leitor pode ser induzido à falsa e prematura conclusão de que no caso de gestação de feto anencefálico há conflito entre os direitos identificados acima. Pode-se também concluir que num primeiro momento tende-se a prestigiar qualquer forma de preservação da vida e, por isso, cria-se desde então uma tendência de se afirmar que o direito à vida do nascituro deve prevalecer.

Ocorre que no caso particular não há sequer vida em perspectiva. 0 progresso tecnológico à disposição das pessoas atualmente é tal que com certeza e exatidão a ecografia identifica a ocorrência ou não da anomalia absolutamente incompatível com a vida extra-uterina. É dizer, o feto portador de anencefalia não tem qualquer chance de sobreviver, a não ser por poucos minutos e, quiçá, poucas horas ou mesmo dias. Isso porque "a parte remanescente do cérebro é sempre exposta, ou seja, não protegida ou coberta por ossos ou pele. A criança é comumente cega, surda, inconsciente e incapaz de sentir dor". 
(FERNANDES, 2007, p. 114).

Por fim, não é preciso ser especialista no assunto para se chegar à conclusão de que sem a formação do sistema nervoso central o feto não tem qualquer chance de sobrevivência. 0 mesmo não se pode dizer em relação ao direito à saúde da gestante. Este é profundamente arranhado.

Com efeito, para a Organização Mundial de Saúde, saúde é um estado de completo bem-estar físico-mental e social e não apenas a ausência de doença ou enfermidade. Parafraseando a pesquisadora Maíra Costa Fernandes, a vida da gestante corre sérios riscos com a gravidez de feto anencefálico, já que não raras vezes o feto morre ainda no ventre materno e quando não, são elevados os riscos de hemorragia, descolamento prematuro de placenta, além de aumento de possibilidade de contrair doenças hipertensivas, pré-eclâmpsia e mesmo eclâmpsia, não sendo difícil também a ocorrência de desmaios e convulsões.

Não bastasse isso, a questão psicológica é foco também de discussão. Isso porque levar a termo normal gravidez de que o resultado se sabe com certeza é um ser natimorto abala seriamente tanto o psicológico da gestante como o de seus familiares, situação dramática, poética e fielmente retratada pelo Ministro do Supremo Tribunal Federal Carlos Ayres Brito, ao votar na ADPF nํ5ㄴ ${ }^{3}$, que tramita na

\footnotetext{
${ }^{3}$ A Confederação Nacional dos Trabalhadores na Saúde (CNTS), em junho de 2004, pediu que o Supremo Tribunal Federal (STF) fixasse entendimento de que antecipação terapêutica de parto de feto anencefálico (ausência de cérebro) não é aborto e, com isso, permitisse que gestantes em tal situação tivessem o direito de interromper a gravidez sem a necessidade de autorização judicial ou qualquer outra forma de permissão especíica do Estado. A CNTS pediu que o Supremo reconhecesse $\mathrm{o}$ descumprimento desses preceitos fundamentais em relação à mulher, nos casos em que as normas penais são interpretadas de forma a impedir a antecipação terapêutica de partos de fetos anencefálicos e que seja dada interpretação conforme a Constituição dos artigos 124, 126 e 128, incisos I e II, do Código Penal, para declarar inconstitucional, com eficácia erga omnes (para todos) e efeito vinculante, a aplicação desses dispositivos para impedir a intervenção nos casos em que a anomalia é diagnosticada por médico habilitado. Requereu, também, a concessão de liminar para suspender o andamento de processos ou anular os efeitos de decisões judiciais que pretendam aplicar ou tenham aplicado os dispositivos do Código Penal para caracterizar como
} 


\section{Suprema Corte:}

Uma crisálida que jamais, em tempo algum, chegará ao estádio de borboleta (...) Ele, ser ainda alocado no ventre "materno", que padece de uma teratologia tal que antecipa esta dilacerante certeza: a certeza de que dele nem sequer é possível dizer que tem hora marcada para morrer (...) porque já vai nascer cerebralmente morto! Com o que se despedaçam por antecipação os mais dourados sonhos, as mais alentadoras expectativas, os mais afetivos planos, as mais lúdicas fantasias que soem permear o encantado universo da mulher às vésperas de ser mãe (...) gravidez e parto de um ser que já se sabe prometido ao túmulo, antes mesmo de conhecer o

aborto a interrupção desses tipos de gravidez. 0 relator da ação é o ministro Marco Aurélio, que deferiu a liminar requestada, diante da relevância do pedido e do risco de manter-se com plena eficácia o ambiente de desencontros em pronunciamentos judiciais até aqui notados, determinando não só o sobrestamento dos processos e decisões que tratem do crime de abortamento de feto anencéfalo não transitadas em julgado, como também o reconhecimento do direito constitucional da gestante de submeter-se à operação terapêutica de parto de fetos anencefálicos, a partir de laudo médico atestando a deformidade, a anomalia que atingiu o feto. 0 Plenário do Supremo Tribunal Federal (STF) retomou no dia 20 de outubro de 2004, a discussão sobre a legitimidade constitucional da antecipação de parto de feto anencefálico (sem cérebro), com o julgamento da Argüição de Descumprimento de Preceito Fundamental (ADPF) 54, proposta pela Confederação Nacional dos Trabalhadores na Saúde (CNTS). Os ministros, por maioria, decidiram revogar a liminar deferida pelo relator, ministro Marco Aurélio, mantendo, todavia, o sobrestamento das ações em curso e das decisões que ainda não transitaram em julgado. 0 procurador-geral da República da época, Claudio Fonteles, suscitou questão de ordem questionando, de forma preliminar - ou seja, antes da análise do mérito - a adequação da ADPF para analisar o pedido da CNTS, cabendo ao Plenário decidir pela admissibilidade ou não da ação. Na retomada do julgamento da Argüição de Descumprimento de Preceito Fundamental (ADPF) 54, os ministros do Supremo Tribunal Federal analisaram, no dia 27 de abril de 2005, o cabimento da ADPF proposta pela Confederação Nacional dos Trabalhadores na Saúde (CNTS). Por sete votos a quatro, os ministros resolveram dar seqüência à tramitação do processo no Supremo, para posterior decisão quanto à legalidade da interrupção de gravidez de fetos anencefálicos (ausência de formação cerebral). Votaram a favor os ministros Marco Aurélio (relator), Carlos Ayres Britto, Joaquim Barbosa, Gilmar Mendes, Celso de Mello, Sepúlveda Pertence e Nelson Jobim (presidente). Negaram seguimento à ação os ministros Eros Grau,

Cezar Peluso, Ellen Gracie e Carlos Velloso. Atualmente o processo está concluso com o relator. Esta fase processual foi consultada no dia 03 de Janeiro de 2008. 
berço (...) o martírio de levar às últimas conseqüências uma tipologia de gravidez que outra serventia não terá senão a de jungir a gestante ao mais doloroso dos estágios: o estágio de endurecer o coração para a certeza de ver seu bebê involucrado numa mortalha.

Além disso, soem permear o universo da gestante de feto anencefálico os seguintes sentimentos: ambivalência, culpa, impotência, perda do objeto amado, choque, raiva, tristeza e frustração.

Convém ressaltar, ainda, a repercussão coletiva em decorrência do entendimento de que a interrupção de gravidez de feto anencefálico é conduta proibida por nosso ordenamento jurídico. Certamente isso incentiva a clandestinidade de ações abortivas sem qualquer condição de higiene e segurança e implica em sérios riscos à saúde da gestante.

Diante desse "conflito aparente" entre direitos não há dúvida de que se deve prestigiar o direito à saúde da gestante protegido especificamente por nossa Constituição quando em seu artigo 196 estatui que o direito à saúde é um direito de todos, constituindo um dever do Estado sua efetivação. Deve-se, portanto, autorizar, mediante consentimento esclarecido, a realização da interrupção da gravidez.

\section{O PRINCÍPIO DA DIGNIDADE DA PESSOA HUMANA E SUA REPERCUSSÃO NO TEMA}

Antes de tratar do assunto diretamente, convém questionar: o que é princípio? A idéia que se tem é a de que princípio é a gênese, é o começo, é aquilo que para ser o que é, depende de. Juridicamente, por outro lado, não é fácil a tarefa de conceituá-lo. Dentre as proposições doutrinárias acerca do conceito, a de Cristiano Chaves de Farias é bastante interessante porque reúne concisamente a essência do vocábulo. Para o jurista baiano, princípios são "proposições genéricas que servem de substrato para a organização de um ordenamento jurídico. São, portanto, as bases sobre as quais se constrói o sistema". 
(FARIAS, 2005, p. 32). Como ressaltado na introdução deste artigo a influência das regras nos aplicadores da lei ainda é bastante forte sendo certo que ainda hoje há aqueles que refutam a eficácia normativa dos princípios por entenderem, em suma, que eles deixam ao alvedrio subjetivo do intérprete sua abrangência.

A despeito disso, para a moderna doutrina constitucional não há qualquer hesitação. Os princípios têm sim eficácia normativa e isso decorre precisamente do fato de o legislador lançar mão de preceitos principiológicos justamente por reconhecerem a própria incapacidade de regulamentarem com proposições predeterminadas (regras) todas as possibilidades de condutas humanas em decorrência do dinamismo das relações sociais.

Os princípios indubitavelmente possuem permeabilidade frente aos valores ético-jurídicos surgidos num dado corpo social num dado momento e por isso mais abrangentes são. Como preleciona Barroso (2007, pp. 167 -168):

A banalização do mal ao longo da primeira metade do século XX e a constatação, sobretudo após as experiências do fascismo e nazismo, de que a legalidade formal poderia encobrir a barbárie levaram a superação do positivismo estrito e ao desenvolvimento de uma dogmática principialista, também identificada como pós-positivismo.

É inevitável a conclusão de que com a promulgação da Constituição acabou-se com aquele hiato que existia entre as cartas anteriores e a legislação infraconstitucional havendo a necessidade de sempre que se for analisar um instituto fazê-lo em conformidade com o que estatui nossa Carta Magna. Com o seu advento, vários direitos e garantias foram erigidos à qualidade de fundamentais, ganhando essa especial dignidade pela importância que representam à Sociedade e seus entes, como assecuratórios de um dos principais fundamentos da República Federativa do Brasil contido no artigo 1丷, inciso III, que é a dignidade da pessoa humana. 
Depois do princípio da soberania, que autoriza um povo a escolher livremente o direito a que se quer ver submetido (noção Kantiana), o princípio da dignidade da pessoa humana parece o mais importante do ordenamento jurídico e aquele que tem despertado maior dedicação por parte dos operadores do direito. Na abalizada lição de Sarlet (2007, pp. 236 - 237), um dos maiores estudiosos do assunto, referido princípio consiste:

Na qualidade intrínseca e distintiva reconhecida em cada ser humano que o faz merecedor do mesmo respeito e consideração por parte do Estado e da comunidade, implicando, neste sentido, um complexo de direitos e deveres fundamentais que assegurem a pessoa tanto contra todo e qualquer ato de cunho degradante e desumano, como venham a lhe garantir as condições existenciais mínimas para uma vida saudável, além de propiciar e promover sua participação ativa e coresponsável nos destinos da própria existência e da vida em comunhão com os demais seres humanos.

A dignidade da pessoa humana, enfim, "identifica um espaço de integridade moral a ser assegurado a todas as pessoas por sua só existência no mundo". (BARROSO, 2007, p. 168).

Traduzindo a extensão conceitual desse princípio, pode-se fazer uma dissociação analítica de seus termos. Dignidade é uma respeitabilidade máxima alcançada em razão da graduação havida. Assim, por dignidade da pessoa humana há de se entender como qualquer proposta que tenha por fim respeitar a pessoa humana no seu modo peculiar de existir em sociedade não somente como objeto de ação própria ou de terceiros, mas também como geradora de direitos fundamentais (negativos).

A dignidade da pessoa humana, portanto, não é apenas uma dádiva, mas também prestação e reconhecimento. Dela irradiam em linhas gerais, segundo Moraes apud Sarlet (2007, pp. 234 - 235), outros quatro princípios jurídicos fundamentais, a saber: igualdade, liberdade, integridade física e moral e solidariedade. 
Ora, levar uma vida digna é levar uma vida equilibrada, em consonância com o seu propósito moral, é ser respeitado em sua liberdade e privacidade, receber tratamento igualitário, desde que estes não atinjam negativamente a esfera do próximo.É, enfim, poder estar bem consigo mesmo.

A despeito do posicionamento do Superior Tribunal de Justiça anteriormente citado, ecoado pela Ministra Laurita Vaz, digno de respeito por representar a expressão de um Poder da República, o raciocínio levado a cabo de que somente as causas previstas no artigo 128 do Código Penal podem excluir o caráter criminoso da conduta desenvolvida ofende diametralmente o princípio insculpido no artigo 1ํㅡㄹ inciso IV da Constituição em suas quatro irradiações.

Ofende a igualdade porque impõe discriminação arbitrária e fundada na qualidade da pessoa, que é mulher. Subjuga-a, enfim. Não há, com efeito, em nosso direito nada comparável à arbitrariedade da obrigação imposta à mulher como a de levar a cabo gestação fracassada em relação ao homem. Nem se fale que isso é óbvio porque o homem não tem a capacidade gestatória. É claro que não tem! Vejamos a lucidez do escólio de Sarmento (2007, p. 47):

A Constituição de 88, neste particular, foi taxativa: "homens e mulheres são iguais, nos termos desta Constituição" (art. $5^{\circ}$, inciso I). Porém, há ainda muito a se avançar para que se cumpra o mandamento constitucional. E uma das tarefas urgentes é a revisão do "entulho machista": normas elaboradas no passado por um legislativo composto quase exclusivamente por homens, que refletem estereótipos impregnados de preconceitos, e que implicam no congelamento ou até no aprofundamento da desigualdade entre os gêneros.

Atinge, outrossim, a liberdade da gestante, que fica com sua autonomia ética coarctada e, portanto, sua liberdade pessoal restringida pela vontade de pessoas que nada têm a ver com o problema que a aflige. Nesse sentido, cabe a lição de Dworkin (2003, p. 342): 
Contudo, ainda que possamos sentir que nossa própria dignidade está em jogo nas atitudes que os outros tomam diante da morte e que às vezes possamos desejar que os outros ajam como nos parece correto, uma verdadeira apreciação da dignidade argumenta decisivamente na direção oposta em favor da liberdade individual e não da coerção.

E arremata o insigne filósofo:

Mesmo as pessoas que querem impor suas conviç̧ões a todos por meio do direito criminal, quando elas e seus colegas, que pensam do mesmo modo, são politicamente poderosos, ficariam horrorizadas, talvez a ponto de deflagrar uma revolução, se ocorresse uma inversão de sua sorte política e se vissem diante da perda da liberdade que agora pretendem negar aos demais.

A obrigatoriedade de levar a termo gravidez de feto anencéfalo fere, também, a integridade física e mesmo moral da mulher. Ambas aqui já tratadas e seriamente comprometidas com o "dever legal" imposto de aguardar o parto de ser que certamente não sobreviverá. As perguntas comumente formuladas pelas pessoas de "como vai o bebê?", o pedido para ver uma fotografia, a oferta de ajuda quando necessário, etc., ao contrário de promover orgulho e inspiração promoverão desconcerto, indignação.

E por fim, acaba com a solidariedade, na medida em que não garante a coexistência humana em suas diversas manifestações. De fato, obrigar uma mãe a levar a cabo gravidez cujo feto não sobreviverá é obrigar arbitrariamente uma pessoa a realizar conduta sem qualquer repercussão na vida de quem está obrigando e com graves e funestos efeitos na pessoa obrigada ferindo de morte a fraternidade exigida para uma sociedade melhor.

0 homem, nas palavras de Bobbio (2004, p. 68) é "um animal teleológico que atua geralmente em função de finalidades projetadas no futuro" e é claro que na consecução de seus propósitos não pode, de forma absoluta, arranhar a respeitabilidade ao próximo, pois as- 
sim agindo estará autorizando que se faça o mesmo com ele e dessa forma, a célula do direito, que é a pessoa humana, estará sendo prejudicada.

\section{7. $O$ PRINCÍPIO DA LEGALIDADE E A ATIPICIDADE PENAL DA CONDUTA DE INTERROMPER A GRAVIDEZ DE FETO ANENCEFÁLICO}

0 artigo 5º, inciso X da Constituição da República de 1988, estatui que ninguém é obrigado a fazer ou deixar de fazer algo, senão em virtude de lei. No citado artigo encontra-se a previsão constitucional do princípio da legalidade, que na lição de Tavares (2007, p. 581) "reparte-se, como visto acima, em dois fronts. Em primeiro, exige respeito à lei posta. Em segundo lugar, impõe que não se crie direito ou dever sem amparo legal; se não há lei, não há suporte para qualquer exigência ou benefício público".

Daí surge o debate jurídico. Afinal, interromper a gravidez de feto anencefálico é abortamento criminoso? A resposta que se impõe é negativa. 0 crime de abortamento previsto no Código Penal nos artigos 124, 125 e 126 exige naturalmente perspectiva de vida. Se o bem jurídico tutelado nas condutas criminosas é justamente a vida do feto e se este feto não terá qualquer chance de sobrevida parece óbvia a conclusão de que o fato é atípico diante da falta de viabilidade do feto. Nesse sentido são as posições de Guilherme de Souza Nucci (2006, pp. 594-595) e Carlos Ayres Brito em seu voto na ADPF no 54.

Para grande parte da doutrina penal analiticamente crime é fato típico, ilícito e culpável. Carecendo de qualquer um dos elementos antes mencionados, crime não há.

A doutrina formalista entende que fato típico é a reunião de conduta, resultado, nexo de causalidade e adequação típica. A análise da interrupção da gravidez de feto anencefálico é realizada já na primeira fase de configuração do crime, isto é, na análise do fato típico e reside precisamente no nexo de causalidade. 
0 artigo 13 do Código Penal, que trata do assunto, prevê em sua primeira parte que "o resultado, de que depende a existência do crime, somente é imputável a quem lhe deu causa". 0 Código Penal, segundo a maioria dos doutrinadores, adotou a teoria da equivalência das condições, também conhecida como teoria da equivalência dos antecedentes ou teoria da condição simples ou generalizadora. Para essa teoria "quaisquer das condições que compõem a totalidade dos antecedentes é causa do resultado, pois a sua inocorrência impediria a produção do evento". (NUCCI, 2002, p. 98).

A questão é: o resultado morte ou pelo menos a possibilidade de a morte ser alcançada (no caso de tentativa), é imputável à mãe e/ou ao médico que desenvolveram a conduta? Para a teoria dos antecedentes, embora discutível, pode-se chegar à conclusão que sim, pois a interrupção da gravidez funcionaria como concausa para a ocorrência da morte e, por isso, não haveria qualquer corte no nexo causal. Mãe e/ou médico responderiam, portanto, pelo crime.

Por essa razão, sobreleva registrar que parte da doutrina penal mais moderna está difundindo também uma nova perspectiva de análise do fato típico somando ao ensinamento da doutrina formalista uma análise ulterior de ocorrência ou não de ofensividade, lesividade como querem alguns.

Para essa corrente, uma leitura constitucional do Direito Penal e da teoria do delito é obrigatória à medida que a sanção penal incide justamente sobre bens fundamentais da pessoa (liberdade, patrimônio, etc.). A construção de todo o sistema penal constitucionalmente orientado, em conseqüência, deve partir da premissa de que não há crime sem ofensa - lesão ou perigo concreto de lesão - a um bem jurídico.

Assim, fato típico só será quando o bem jurídico valorado pela norma vem a ser lesionado ou exposto a perigo concreto. Conforme entendimento de Gomes (2002, p. 42), "certo é que esse bem jurídico deve ser suscetível de ofensa, deve ser uma entidade passível 
de ofensa, porque de outra maneira não se cumpriria o princípio de ofensividade".

Referido princípio, que está sendo propagado entre os doutrinadores e tribunais pátrios irradia seu comando na teoria da imputação objetiva, originada em 1927, na Alemanha, e que em síntese:

Exige, para que alguém seja penalmente responsabilizado por conduta que desenvolveu, a criação ou incremento de um perigo juridicamente intolerável e não permitido ao bem jurídico protegido, bem como a concretização desse perigo em resultado típico. (NUCCI, 2006, p. 197).

Assim, a atribuição de um resultado a uma pessoa não é determinada apenas pela relação de causalidade, mas é necessário um outro nexo, de modo que esteja presente a realização de um risco proibido pela norma ou a criação ou o incremento de um perigo juridicamente intolerável. Por isso mesmo os seus defensores afirmam categoricamente que a adoção da teoria da imputação objetiva transcende o contexto do nexo causal.

Sua aplicação não prescinde da teoria da equivalência das condições. Ao revés, o liame causal preconizado no artigo 13 do Código Penal é observado, mas antes de se partir para a análise de se houve dolo ou culpa, a teoria da imputação objetiva exige que seja verificado se a conduta desenvolvida criou para a vítima um risco proibido pela norma ou criou ou incrementou um perigo juridicamente intolerável.

A pergunta é: Ao antecipar o parto de feto anencefálico, a mãe e/ ou o médico criaram ou incrementaram um perigo juridicamente intolerável e não permitido ao bem jurídico tutelado (a vida, no caso)? A resposta é negativa. Ao contrário, como visto acima, afastou-se perigo juridicamente intolerável, que era ofensa ao direito à saúde da gestante, à dignidade da pessoa humana, à sua liberdade, e à sua integridade física e moral. Não há bem jurídico a ser ofendido também porque não há sequer viabilidade de vida cientificamente comprovada. Por essa razão, em nenhum momento o feto foi exposto a risco ou 
perigo além do qual sua própria sorte o atribuiu.

Registre-se que a teoria da imputação objetiva é uma alternativa à teoria da equivalência e a auxilia na resolução e completo entendimento e caracterização de fatos como o analisado ainda na quadra do fato típico.

Dessa forma, a equação do problema é a seguinte: Houve conduta (interrupção da gravidez de feto anencefálico), houve resultado (a morte do feto em razão do completo desligamento com sua genitora), há liame entre a conduta e o resultado (isto é, da interrupção da gravidez decorreu a morte do feto, que só sobrevivia à custa da genitora, já que ao nascer infalivelmente morreria em razão exclusivamente de sua anomalia), mas não se criou para a vítima um risco proibido pela norma nem se criou ou incrementou um perigo juridicamente intolerável.

Esse raciocínio autoriza, igualmente, e, portanto, a conclusão de que a interrupção da gravidez de feto anencefálico é fato atípico porque não lesa nenhum bem, nem tão pouco causa perigo concreto porquanto a morte advém de fato estranho à conduta desenvolvida já que era evento certo e com termo certo, isto é, dependia exclusivamente da expulsão natural do feto do ventre materno. À luz desse raciocínio, portanto, está afastada a configuração de fato típico da conduta de antecipar o parto de feto anencefálico.

\section{O PRINCÍPIO DA PROPORCIONALIDADE COMO INS- TRUMENTO DE INTERPRETAÇÃO DO CASO}

Num ordenamento jurídico repleto de princípios e regras como é o arcabouço jurídico brasileiro há a necessidade de um critério regulador da harmonia dessas normas e que atue como instrumento de contenção da discricionariedade do poder estatal frente aos direitos fundamentais eleitos pelo povo e constantes na Lei Maior. É aqui que ganha contorno e especial importância o princípio da proporcionalidade, cuja teorização é recente. 
Como preleciona Tavares (2007, p. 678) "a proporcionalidade, numa primeira aproximação, é a exigência de racionalidade, a imposição de que atos estatais não sejam desprovidos de um mínimo de sustentabilidade".

Nessa esteira, analisando a situação jurídica atual do abortamento de feto viável oriundo de estupro e a comparando com a imposição à mulher de levar a termo gravidez de feto inviável (portador de anomalia incompatível com a vida extra-uterina), a outra conclusão não se pode chegar senão a de que esta imposição denota ser desproporcional ao que dispõe nosso ordenamento jurídico, especificamente o previsto no artigo 128, inciso II, do Código Penal. Este dispositivo agasalha uma causa de exclusão de ilicitude da conduta da mulher que foi vítima de estupro, engravidou e optou por não dar à luz a criança. A opção do legislador já em 1940 era a de prestigiar a liberdade da mulher, especialmente a possibilidade de ela escolher o parceiro e futuro pai de seu filho.

A pergunta que se faz é a seguinte: É proporcional prestigiar a liberdade da mulher autorizando-a a abortar feto viável decorrente de estupro e, noutra situação, obrigá-la a levar a cabo gravidez de feto de que se tem certeza não sobreviverá ao parto? A resposta que se desenha só pode ser negativa.

Num Estado Democrático de Direito como é a República Federativa do Brasil é imprescindível lançar mão do princípio da proporcionalidade como forma de acomodar os diversos interesses em jogo, "pois é uma degradação da pessoa a objeto, se ela for importunada pelo emprego de meios mais rigorosos do que exige a consecução do fim de bem-estar da comunidade". (GUERRA FILHO apud TAVARES, 2007, p. 680).

Nesse contexto, os valores preservados nas duas situações denotam estar absolutamente desbalanceados havendo a necessidade de interferência do intérprete da lei para se atingir a mais oportuna relação de equilíbrio de valores. 
Assim, pode-se retirar da própria vontade do legislador de 1940 o norte para o deslinde do caso. Se naquela época, ainda que o feto fosse viável, ele preferiu a liberdade da mulher, com muito mais razão hoje (no caso de anomalia incompatível com a vida extra-uterina do feto), ele prefere a liberdade da mulher, especialmente porque neste caso outros princípios (da dignidade da pessoa humana, suas irradiações e da legalidade) e direitos (à saúde da gestante) estão em jogo.

\section{CONSIDERAÇÕES FINAIS}

A Constituição da República, como compilação de decisões políticas fundamentais do povo brasileiro, está no vértice de nosso sistema normativo e, por isso mesmo, é o fundamento de validade de todas as demais normas. Dessa forma, toda lei e ato normativo editados em discordância com sua letra ou incompatível com o seu espírito não têm lugar em nosso ordenamento. Enfim, para que tenham legitimidade e validade devem estar sintonizados com a mensagem proposta pelo constituinte.

Não há dúvida de que nossa Constituição é eminentemente dirigente, programática e principiológica, sendo tarefa precípua do Poder Judiciário, na análise do caso concreto, interpretar os preceitos constitucionais (regras e princípios) tendo como norte a incessante busca de concretização da mensagem normativa do constituinte.

De tudo que foi exposto verifica-se que a interrupção da gravidez de feto anencefálico visa a garantir o direito à saúde da gestante, obedece ao princípio da dignidade da pessoa humana e suas irradiações (igualdade, liberdade, integridade física e moral, e solidariedade) e está em consonância com o princípio da legalidade, todos previstos no seio da Constituição.

De mais a mais guarda absoluta sintonia com a vontade do legislador e, por conseguinte, com a vontade do povo, que expressamente anuiu e consagrou a liberdade da mulher já em 1940 ao escolher a opção que lhe convier quando aquele direito estiver na iminência de 
ser aniquilado.

Por outro lado, não ofende o direito à vida do feto anencefálico, que comprovadamente não sobreviverá ao parto.

Cabe mencionar a lúcida e brilhante lição de Sarlet (2007, p. 234):

O que se percebe, em última análise, é que onde não houver respeito pela vida e pela integridade física e moral do ser humano, onde as condições mínimas para uma existência digna não forem asseguradas, onde não houver limitação do poder, enfim, onde a liberdade e a autonomia, a igualdade (em direitos e dignidade) e os direitos fundamentais não forem reconhecidos e minimamente assegurados, não haverá espaço para a dignidade da pessoa humana e esta (a pessoa), por sua vez, poderá não passar de mero objeto de arbítrio e injustiças.

Assim, a conclusão a que se chega é a de que a conduta desenvolvida é atípica do ponto de vista penal (por não haver criação nem incremento de risco proibido ou exposição a perigo concreto bem jurídico tutelado e por isso mesmo inofensiva ao feto) e agasalhada pelo direito constitucional. Entender de forma diversa é permissa venia, fomentar o desarranjo do ente principal da sociedade, que é o ser humano. É prestigiar a letra fria da lei em detrimento do berço quente $\mathrm{e}$ seguro da Justiça. É intrometer na esfera alheia causando-lhe maior desconforto que o próprio destino já está lhe proporcionando. É ferir diametralmente o princípio constitucional e fundamental, que assegura a todos nós, inclusive ao feto, o direito à vida, mas a uma vida digna, que não haverá no caso em testilha.

\section{REFERÊNCIAS BIBLIOGRÁFICAS}

ALVES Filho, Navantino. et al. Perinatologia Básica. 3. ed. Rio de Janeiro: Guanabara Koogan, 2006. 
BANKOWSKI, Zenon. Vivendo plenamente a lei. Rio de Janeiro: Elsevier, 2007.

BARROSO, Luis Roberto Barroso. Gestação de fetos anencefálicos e pesquisas com células-tronco: dois temas acerca da vida e da dignidade na constituição. In: CAMARGO, Marcelo Novelino (Org.). Leituras Complementares de Constitucional: Direitos Fundamentais. 2. ed. São Paulo: Juspodivm, pp. 167-168.

BOBBIO, Norberto. A era dos direitos. 5. Ed. Rio de Janeiro: Elsevier, 2004 .

CONSULTA de fase processual. Disponível em: http://www.stf.gov.br/ portal $/$ processo $/$ verProcessoAndamento.asp? numero $=54 \&$ classe $=A D P F Q$ $0 \&$ codigoClasse $=0$ \&origem $=J U R \&$ recurso $=0$ \&tipoJulgamento $=M$ ) . Acesso realizado em 03 jan. 2008.

DWORKIN. Ronald. Domínio da Vida. São Paulo: Martins Fontes, 2003.

ENCICLOPÉDIA e Dicionário Koogan/Houaiss. Rio de Janeiro: Editora Guanabara Koogan, 1994, p. 04.

FARIAS, Cristiano Chaves de. Direito Civil: Teoria Geral. 3. ed. Rio de Janeiro: Lumen Juris, 2005.

FERNANDES, Maíra Costa. Interrupção de gravidez de feto anencefálico: uma análise constitucional. In: PIOVESAN, Flávia; SARMENTO, Daniel (Org.). Nos limites da vida: Aborto, clonagem humana e eutanásia sob a perspectiva dos direitos humanos. Rio de Janeiro: Lumen Juris, 2007.

FRIGÉRIO, Marcos Valentin. Aspectos bioéticos, médicos e jurídicos do abortamento por anomalia fetal grave no Brasil. Revista Brasileira de Ciências Criminais. [S.I] v. 41, p. 291, jan./mar. 2003.

GOMES, Joaquim Barbosa. Voto Proferido pelo Ministro Joaquim 
Barbosa Gomes HC nํ 84.025/2004. In: PIOVESAN, Flávia (Org.); SARMENTO, Daniel (Org.). Nos limites da vida: Aborto, clonagem humana e eutanásia sob a perspectiva dos direitos humanos. Rio de Janeiro: Lumen Juris Editora, 2007.

GOMES, Luiz Flávio. Princípio da ofensividade no Direito Penal. São Paulo: Editora Revista dos Tribunais, 2002.

GUERRA FILHO, Willis Santiago. Processo Constitucional e direitos Fundamentais. São Paulo: Instituto Brasileiro de direito Constitucional/ Celso bastos Editor, 1999. Apud TAVARES, André Ramos. Curso de Direito Constitucional. 5. ed. São Paulo: Saraiva, 2007.

MONTENEGRO, Carlos Antonio Barbosa; REZENDE, Jorge de. Obstetrícia Fundamental. 10. ed. Rio de Janeiro: Editora Guanabara Koogan, 2005.

MORAES, Maria Celina Bodin de. apud SARLET, Ingo Wolfgang. As dimensões da dignidade da pessoa humana: Uma compreensão jurídico-constitucional aberta e compatível com os desafios da biotecnologia. In: PIOVESAN, Flávia; SARMENTO, Daniel. (Org.). Nos limites da vida: Aborto, clonagem humana e eutanásia sob a perspectiva dos direitos humanos. Rio de Janeiro: Lumen Juris, 2007, pp. 234235.

NUCCI, Guilherme de Souza. Código Penal Comentado. 2. ed. São Paulo: Revista dos Tribunais, 2002.

Manual de Direito Penal. 2. ed. São Paulo: Editora Revista dos Tribunais, 2006.

REZENDE, Jorge de. Obstetrícia. Rio de Janeiro: Editora Guanabara Koogan, 1969.

SARLET, Ingo Wolfgang. As dimensões da dignidade da pessoa hu- 
mana: Uma compreensão jurídico-constitucional aberta e compatível com os desafios da biotecnologia. In: PIOVESAN, Flávia (Org.); SARMENTO, Daniel. (Org.). Nos limites da vida: Aborto, clonagem humana e eutanásia sob a perspectiva dos direitos humanos. Rio de Janeiro: Lumen Juris, 2007.

SARMENTO, Daniel. Legalização do aborto e Constituição. In: PIOVESAN, Flávia (Org.) SARMENTO, Daniel (Org.). Nos limites da vida: Aborto, clonagem humana e eutanásia sob a perspectiva dos direitos humanos. Rio de Janeiro: Lumen Juris Editora, 2007.

TAVARES, André Ramos. Curso de Direito Constitucional. 5. ed. São Paulo: Saraiva, 2007. 